OPEN ACCESS

Edited by:

Fu Zhao,

Purdue University, United States

Reviewed by:

Graziano Salvalai,

Politecnico di Milano, Italy

Jay Zarnikau,

University of Texas at Austin,

United States

*Correspondence:

Essam Elnagar

essam.elnagar@uliege.be

Specialty section:

This article was submitted to

Sustainable Energy Systems

and Policies,

a section of the journal

Frontiers in Energy Research

Received: 24 March 2020

Accepted: 14 August 2020 Published: 04 September 2020

Citation:

Elnagar E and Köhler B (2020) Reduction of the Energy Demand

With Passive Approaches in Multifamily Nearly Zero-Energy Buildings Under Different Climate

Conditions.

Front. Energy Res. 8:545272. doi: 10.3389/fenrg.2020.545272

\section{Reduction of the Energy Demand With Passive Approaches in Multifamily Nearly Zero-Energy Buildings Under Different Climate Conditions}

\author{
Essam Elnagar ${ }^{1,2 *}$ and Benjamin Köhler ${ }^{2}$ \\ ${ }^{1}$ Energy Systems Research Unit - Thermodynamics Laboratory, Department of Aerospace and Mechanical Engineering, \\ University of Liège, Liège, Belgium, ${ }^{2}$ Fraunhofer Institute for Solar Energy System ISE, Department Energy Efficient Buildings, \\ Freiburg, Germany
}

Nearly zero-energy buildings (nZEBs) will be the standard in Europe in the future. How nZEBs are defined and therefore designed varies amongst Europe due to different national definitions/legislations. Furthermore, finding the optimal building design and technology sets for nZEBs under different boundary conditions (climate, availability of renewable energy sources on-site etc.) and for different building types (residential, nonresidential) is still a challenge. Many studies in the field focus on active technologies and renewable energies in buildings. However, the effects of passive approaches on energy consumption are not quantified. This paper therefore focuses on the quantification of the effects of passive design approaches/technologies to improve the energy performance of buildings. Passive approaches are the basis for finding optimal nZEB technology sets. Technology sets are combinations of different types of technologies in nZEBs for both the satisfaction of energy needs and thermal comfort requirements. In this paper different passive approaches for already realized buildings in different European countries with different climate conditions [Stuttgart (Germany), Kiruna (Sweden) and Palermo (Italy)] are demonstrated. Even though several technologies are available to achieve nZEBs, applying and combining these technologies in an optimal way is still a challenge. Furthermore, higher initial investment costs for nZEBs are an obstacle for the market acceleration of nZEBs. Hence finding the best trade-off amongst the different goals, optimizing the most promising passive approaches that can be applied is a central part of the solution.

Keywords: nearly zero-energy building, energy demand, passive technologies, energy savings, building optimization

\section{INTRODUCTION}

Buildings are responsible for approximately $40 \%$ of energy consumption in the EU (Buildings Performance Institute Europe, 2011). This sector is increasing daily which also increases the energy demand. Therefore, there is a significant need to decrease the total energy consumption which can be achieved by improving the building design, applying highly efficient technologies and decreasing the costs for these technologies. 
In addition, buildings have an important role to play to reduce the $\mathrm{CO}_{2}$ emissions and to mitigate climate change and reduce the overall greenhouse gas emissions by $80-95 \%$ until 2050 below 1990 levels (European Union, 2010).

Existing buildings have effective opportunities for energy savings because the level of performance of these buildings is below the current potentials and standards for energy efficiency requirements (Ferrara et al., 2018). As determined in the European energy performance of buildings directive (EPBD), it is needed to increase the energy efficiency of buildings to achieve the objective of reducing the Union's energy consumption by $20 \%$ until 2020. As heating and cooling in buildings and industry account for half of the EU's energy consumption the need to increase the efficiency in these consumption sectors is high (The European Parliament and The Council of the European Union, 2018).

Determination of the optimized technologies to be applied for improving the energy performance of buildings should be based on a methodology which might not be the same in different buildings depending on the climate and the local conditions for each different region in Europe. Furthermore, there is a large variety of concepts and standards for highly energy efficient buildings. To find the best trade-off between the different goals like decreasing the total energy demand, the optimization of the most promising technologies which can be applied is the solution.

Although, many different types of single technologies are available, the combination of optimized technologies might be limited to a few promising solutions in different buildings and climate zones around Europe. According to (Attia, 2018) central elements of the design of Net Zero Energy Buildings (NZEB) are the reduction of loads and utilization of passive opportunities. Besides that, still needed active systems must be optimized and on-site renewable energies must be incorporated.

There are many technologies that can reduce energy use in buildings which can be divided between passive and active technologies (Cabeza and Chàfer, 2020). The first group can contribute to achieve passive sustainable design like adapting building geometry, natural lighting and natural ventilation and the second group is the energy savings techniques like building envelope design, heat storage system and lighting design. Active design for any building, which is supported by active technologies, includes infrastructure, architecture and devices that use or produce electricity, heat or cold, store energy and assure good air and indoor environmental quality (Tzortzaki, 2017).

Passive design for any building includes infrastructure, architecture and devices that achieve a result by directly using natural forces/ambient energy without conversion like e.g., passive/free ventilation, night cooling, shading technology, daylighting and adjustments of the building envelope by changing window to wall ratio (WWR), building orientation, glazing and green roofs to reduce the energy demand for heating, cooling, ventilation and lighting. The aim of passive strategies is to make the best use of natural resources and adjust the building design. For example, daylighting optimization helps to reduce the energy demand related to artificial lighting, which makes up $14 \%$ of electrical consumption in the European Union and $19 \%$ worldwide (Zissis, 2019). It can be integrated with shading systems as well to reduce the energy demand for heating and cooling depending on local conditions.

There are few studies addressing the combination of passive approaches in residential buildings to improve the energy efficiency and to achieve the energy efficient buildings standards as stated below. Most studies focus on non-residential buildings.

Birtles et al. (1996) as well as Kolokotroni et al. (2001) analyzed the effects of night and free ventilation on summer comfort in office and educational buildings. They showed that even with simple controls based on the ambient temperatures the comfort could be improved. Schulze and Eicker (2013) assessed possible savings in cooling energy demands of office buildings with natural ventilation under different climate conditions and showed saving potentials of 13 to $44 \mathrm{kWh} / \mathrm{m}^{2} \mathrm{a}$. Salvalai et al. (2013) demonstrated five cooling concepts to assess the impact of natural night ventilation on the building performance. The mechanical night ventilation provides high discomfort for the three analyzed climates: in Milan the exceeding hours of comfort limit is higher than $30.1 \%$. In Palermo, the night ventilation strategies have a low cooling potential due to high mean ambient air temperature, the exceeding of comfort level is about $75.8 \%$. A similar approach is described in Engelmann et al. (2014), in which the performance of different cooling concepts are compared energetically in different European climate regions. Artmann et al. (2007) showed the climate potential for nighttime ventilation in Europe. It was shown that there is significant passive cooling potential by natural ventilation in Northern Europe. In Central, Eastern and some regions of Southern Europe, a series of warmer nights can occur where passive cooling by nighttime ventilation might not be enough to achieve thermal comfort.

According to (Gago et al., 2015), the existing daylighting standards in many European countries are more or less informative and are not intended to be applied in a prescriptive manner. All the systems discussed in the paper and/or strategies of control of natural light guarantee the penetration of natural light into the building, thus reducing the electrical energy consumption for lighting and cooling. They simultaneously improve the thermal and visual comfort of the users of a building.

The aforementioned studies didn't focus on optimizing the building orientation and its effect on reducing the overall energy demand. Furthermore, they usually focused on only one passive approach. Also, the main focus of the different studies is the combination between daylight and shading system, but the effect of window to wall ratio and its correlation with daylight and shading systems is not quantified yet in many studies. Furthermore, a quantification of different passive approaches in residential buildings in the European context was not investigated adequately yet. In contrast to most studies in the field, by assessing different passive approaches on their own and combining the identified best cases, not only single effects on the energy demand of a building, but also interactions (positive and/or negative) between the assessed passive approaches can be identified and quantified. 


\section{METHODOLOGY}

The identification of efficient and cost-effective technology sets considering passive (design) approaches, active and renewable technologies is highly influenced by local site conditions. Essential for realizing nZEBs is the minimization of the energy demand of a building by a high-quality thermal envelope and a building design suitable for local (climate) conditions. Thereby, passive approaches can play an important role and are therefore assessed in detail in this paper. For the analysis detailed building simulations with EnergyPlus are utilized. The application of different scenarios through diverse measurements is a key approach.

The focus in this paper is to assess the low and nocost technologies. Analyzed passive technologies are a highly insulated building envelope as the basis for reducing the energy demand. A key role for the minimization of the energy demand are the building orientation, window to wall ratio (WWR) and external fixed as well as controlled shading. Furthermore, the optimal utilization of daylight through daylighting control and the effect of natural ventilation strategies on the cooling demand are assessed.

In this paper, the analysis for one residential building in three different climate regions to study the effect of the passive approaches on the heating demand in moderate and cold climate regions as well as on the cooling demand in hot climates is presented. In addition, effects on the electricity demand for lighting is assessed. The analyzed building is a south-oriented multifamily building with 12 dwellings located in EggensteinLeopoldshafen in Germany. The building has four stories and in each story there is one two-room, one three-room and one fourroom apartment. The conditioned building area is $1,119 \mathrm{~m}^{2}$. The gross wall area is $745 \mathrm{~m}^{2}$ and the window are $167 \mathrm{~m}^{2}$ (WWR approx. 22\%). The roof and floor areas are $280 \mathrm{~m}^{2}$ each. The $U$-values of the different building elements are:

- External wall: $0.21 \mathrm{~W} /\left(\mathrm{m}^{2} \mathrm{~K}\right)$

- Windows: $0.7 \mathrm{~W} /\left(\mathrm{m}^{2} \mathrm{~K}\right)$

- Roof: $0.16 \mathrm{~W} /\left(\mathrm{m}^{2} \mathrm{~K}\right)$

- Floor: $0.41 \mathrm{~W} /\left(\mathrm{m}^{2} \mathrm{~K}\right)$

The boundary conditions of the building itself and its climate conditions are defined using SketchUp and OpenStudio. Furthermore, all internal loads are defined in the building model in order to simulate the overall energy demand including electricity for appliances.

Different simulations in different climate regions like in southern part of Italy and in and northern part of Sweden as well as in Germany are conducted. The three different climate conditions are namely Stuttgart (Germany), Kiruna (Sweden) and Palermo (Italy). For the simulations, International Weather for Energy Calculations (IWEC) files published by ASHRAE for the named locations were used (American Society of Heating, Refrigerating and Air-Conditioning Engineers, U.S. Department of Energy's, and National Renewable Energy Laboratory, 2001American Society of Heating, Refrigerating and Air-Conditioning Engineers, U.S. Department of Energy's, and
National Renewable Energy Laboratory, 2001). For the passive approaches all are defined and analyzed in all the locations with different iterations. All iterations conducted are compared to the base case (south orientation).

\section{Building Envelope}

The first assessed approach is the building envelope by varying the building orientation and window to wall ratio. Both parameters have a high influence on solar gains, but also transmission heat losses as windows usually have weaker $U$-values than opaque envelope elements. Thus, both parameters strongly influence the heating and cooling demand of a building. They furthermore influence the availability of daylight inside the building and thereby the electricity demand for lighting.

\section{Building Orientation}

The optimal orientation of the building is not the same in the different climate conditions. The optimal orientation can also be influenced by other site conditions like neighboring buildings. The original orientation of the assessed building is south oriented. Eight orientations are assessed: south (base case), south-east, east, north-east, north, north-west, west and south-west.

\section{Window to Wall Ratio}

The windows usually have the highest $U$-value of all envelope elements. Therefore, the WWR and window overall area have a strong influence on the heating and cooling demand as well as the energy demand for lighting if daylighting control is applied. Besides that, windows are necessary for other passive approaches like e.g., free ventilation. The WWR is assessed through three iterations by increasing the WWR in different sides of the building:

- "WWR1": increasing window area on the east side of the building to an overall WWR of $28.2 \%$

- "WWR2": increasing window area on the west side of the building to an overall WWR of $23.9 \%$

- "WWR3": increasing window area on the east and west side of the building to an overall WWR of $33.8 \%$

\section{Daylighting}

The total electricity consumption for lighting and its share in the total electricity consumption in Stuttgart decreased since 1996 (Federal Ministry for Economic Affairs and Energy, 2015). Reasons are the increased efficiency of light sources, control gears and reflection materials in light bulbs. It is assumed that the electricity consumption for lighting in buildings can be further reduced by 50 to $82 \%$ until 2050 (licht.de, 2008; Wietschel et al., 2010). For achieving this goal, the use of daylight is essential, which can be done by the control of artificial light based on the actual availability of sunlight. Therefore, the effect of daylight control is assessed. Daylighting control is implemented in each apartment. In order to realize an outcome, the installed artificial lights must be dimmable and automatically switchable based on the measured sunlight availability and presence of people. The effect of daylight control on the electricity demand is assessed for the different WWR-variants described above as well as the base case: 
- "Daylighting control": base case building design with daylighting control

- "WWR1 - Daylighting control": WWR1 with daylighting control

- "WWR2 - Daylighting control": WWR2 with daylighting control

- "WWR3 - Daylighting control": WWR3 with daylighting control

- "WWR3 with shading - Daylighting control": WWR3 with additional fixed shading plus daylighting control

\section{Shading}

The third analyzed passive approach is the installation of additional fixed shading systems/overhangs as well as internal controlled shading (only for Italian case). Shading is required to avoid high heat gains in summer and thereby limit the cooling energy demand, which is mainly relevant in the Mediterranean and in non-residential buildings with large window areas. The increased window area increases the solar gains in winter and thereby reduces the heating demand. However, the higher gains in summer increase the cooling demand. Therefore, shading systems, which allow high gains in winter and low gains in summer, are needed.

There are already balconies installed at the south façade of the building, which can be considered as fixed external shading. In addition, fixed external shading is installed above the southoriented windows and at the east and west façade of the building above which no balconies are installed yet. The effect of additional external shading is only assessed for the variant with a large WWR (WWR3). Furthermore, for the Italian case the installation of controlled internal shading is assessed.

- "WWR3 - Shading": Like WWR3, but with increased fixed external shading areas on the east, south, and west side of the building

- "WWR3 - controlled shading": Like WWR3, instead of additional fixed shading controlled internal blinds are installed. They are controlled based on the solar irradiance on the window area.

\section{Natural Ventilation}

Natural ventilation uses pressure and temperature differences between the in- and outside of a building. It is realized through automated and controlled opening of windows. Natural ventilation is assessed in all apartments. Three variants are simulated for the climate conditions in Palermo based on schedules as well as maximum and minimum indoor and outdoor temperatures:

- "Vent1": in three and four room apartments opening areas of $1.5 \mathrm{~m}^{2}$ to north and $4 \mathrm{~m}^{2}$ to south, in two room apartments $3.5 \mathrm{~m}^{2}$ to south; minimum outdoor temperature $18^{\circ} \mathrm{C}$.

- "Vent2": three and four room apartments opening areas of $1.5 \mathrm{~m}^{2}$ to the north and $6 \mathrm{~m}^{2}$ to the south, in two room apartments $6 \mathrm{~m}^{2}$ to south; minimum outdoor temperature $18^{\circ} \mathrm{C}$.
- "Vent3": like Vent2, but minimum outdoor temperature $17^{\circ} \mathrm{C}$. itemize

First, simulations have shown that only considering natural ventilation leads to reductions in the cooling energy demand of only one to three per cent. Therefore, in the above-mentioned iterations, also controlled shading is considered.

\section{RESULTS}

Passive approaches reduce the overall energy demand of a building. The results are presented for the passive approaches and three different climate regions named above. The base cases have specific energy demands for heating, cooling and lighting of $21.74 \mathrm{kWh} / \mathrm{m}^{2} \mathrm{a}$ in Stuttgart, $69.50 \mathrm{kWh} / \mathrm{m}^{2} \mathrm{a}$ in Kiruna, and $38.97 \mathrm{kWh} / \mathrm{m}^{2} \mathrm{a}$ in Palermo (see Figure 1).

\section{Building Envelope}

In the following, the results connected to changes in the building envelope (orientation, window to wall ratio and shading) are described. The best and worst variations of the building orientation and WWR are summarized in Figure 1. The lowest heating energy demand in Stuttgart and Kiruna is achieved in the base case (south oriented). A deviation from the original orientation leads to an increase in the heating demand of 7 to $18 \%$ in Stuttgart. The minimum and maximum heating demand is 20.72 (south orientation) and $24.45 \mathrm{kWh} / \mathrm{m}^{2} \mathrm{a}$ (North-west orientation), respectively. In Kiruna the increase is 3 to $8 \%$. The minimum heating demand is $68.47 \mathrm{kWh} / \mathrm{m}^{2} \mathrm{a}$ (south orientation) and the maximum is $74.06 \mathrm{kWh} / \mathrm{m}^{2} \mathrm{a}$ (north orientation). In Palermo, the optimal orientation of the building is north. The cooling demand in this case is $5 \%$ lower than in the base case ( $36.02 \mathrm{vs} 45.96 \mathrm{kWh} / \mathrm{m}^{2} \mathrm{a}$ ). Other orientations more to the east and west lead to an increase in the cooling demand of 8 to $21 \%$.

An increase in the WWR is decreasing the heating demand in most cases in Stuttgart and Kiruna. The highest decrease is achieved by an increase of the window area at the east and west façade, which also leads to highest overall WWR. The maximum decrease in Stuttgart is $12 \%\left(18.29 \mathrm{kWh} / \mathrm{m}^{2} \mathrm{a}\right)$ and in Kiruna $2 \%\left(66.78 \mathrm{kWh} / \mathrm{m}^{2} \mathrm{a}\right)$. Adding additional fixed external shading in Stuttgart increases the heating demand to the base case level and in Kiruna leads to a slight increase of $1 \%$ compared to the base case. In hot climate regions an increase of the WWR leads to high increases of the cooling demand of $21 \%$ (WWR2: $46.09 \mathrm{kWh} / \mathrm{m}^{2} \mathrm{a}$ ) to $64 \%$ (WWR3: $62.31 \mathrm{kWh} / \mathrm{m}^{2} \mathrm{a}$ ). Adding additional fixed shading to the variant with the largest WWR minimizes the increase, which is, however, still high $(+22 \%$; $\left.46.45 \mathrm{kWh} / \mathrm{m}^{2} \mathrm{a}\right)$. Installing controlled internal shading devices also reduces the increase compared to the base case $(+34 \%$; $\left.50.77 \mathrm{kWh} / \mathrm{m}^{2} \mathrm{a}\right)$.

\section{Daylighting}

Using the available daylight in buildings as much as possible is important for minimizing the electricity demand for lighting. However, as artificial lighting with LEDs is already very efficient, the achieved savings with daylighting control in absolute 


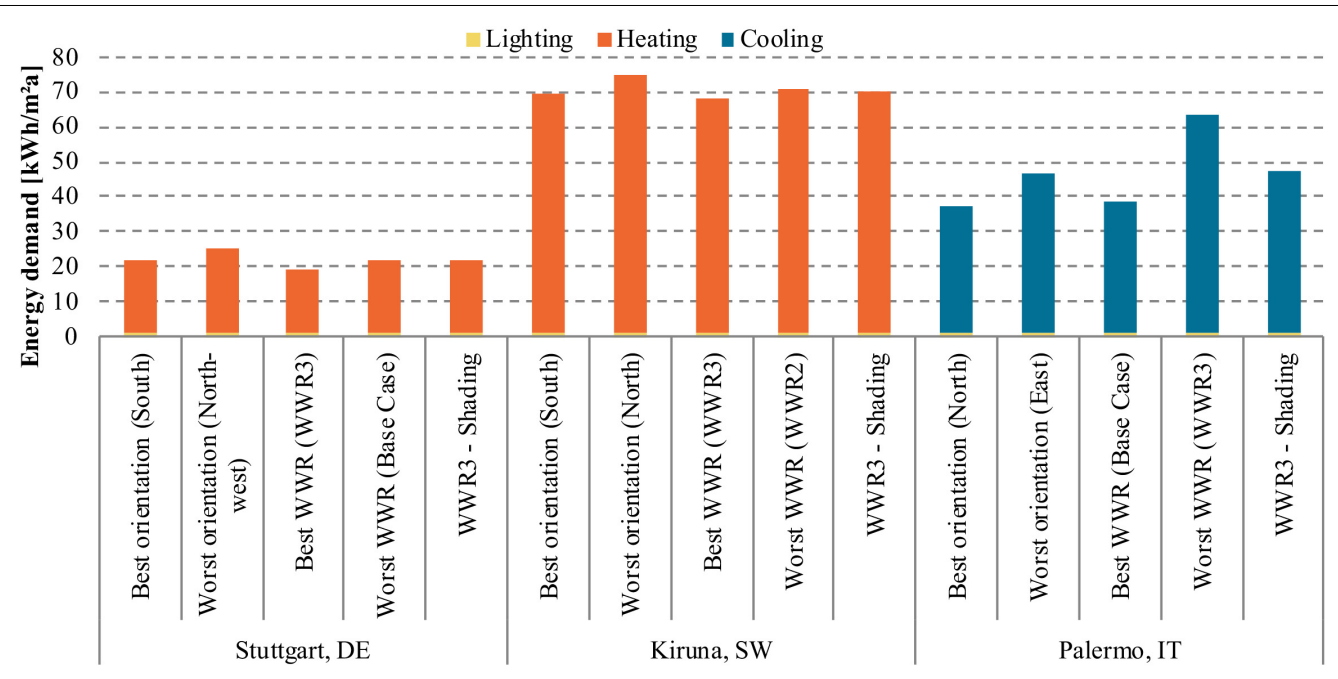

FIGURE 1 | Heating, cooling and electricity for lighting demand due to variations of the building orientation and window to wall ratio in the three assessed climate regions.

numbers is small. In the base case, the building only needs $1.03 \mathrm{kWh} / \mathrm{m}^{2}$ a. In all assessed climate regions, the achieved savings depending on the WWR and additional external shading is between 3 and 9\% (compare Figure 2). The highest savings are achieved in Palermo in the variant with the largest window areas (WWR3 with daylighting control; $0.94 \mathrm{kWh} / \mathrm{m}^{2} \mathrm{a}$ ).

\section{Natural Ventilation}

Natural ventilation in combination with controlled shading can have a high impact on the cooling energy demand of buildings in hot climate areas. The achieved savings for Palermo is between 18 and 22\% (compare Figure 3). The highest savings are achieved with the variant Vent3, which allows comparably low ambient temperatures (only $17^{\circ} \mathrm{C}$, which could be considered too cold by residents). In Vent 3 the energy demand for cooling is reduced from $37.94 \mathrm{kWh} / \mathrm{m}^{2} \mathrm{a}$ in the base case to only $29.55 \mathrm{kWh} / \mathrm{m}^{2} \mathrm{a}$.

\section{Optimum Combinations}

In this section, interactions of the optimum iterations for the different approaches are analyzed. Each location has its optimum iteration for the different passive approaches:

- Stuttgart: South orientation, WWR3, daylighting control in all zones with large WWR

- Kiruna: South orientation, WWR3, daylighting control in all zones with large WWR

- Palermo: North orientation, WWR1, daylighting control in all zones with large WWR, Vent3

The results are based on simulating each approach separately or in combination of maximum one other passive approach. The results presented in the following are based on running one interactive simulation for each region. For Stuttgart and Kiruna mainly the effects on heating and electricity demand for lighting are of interest and therefore assessed. For Palermo, electricity demand for lighting and cooling demand are analyzed.
The achieved savings are shown in Figure 4. In the optimum case of Stuttgart, the specific electricity demand for artificial lighting is $0.96 \mathrm{kWh} / \mathrm{m}^{2} \mathrm{a}$ and the heating demand is $18.30 \mathrm{kWh} / \mathrm{m}^{2} \mathrm{a}$. The achieved saving is $11.4 \%$ while the theoretical overall savings from each separate approach is $11.3 \%$. The combination of the single approaches leads to slightly better results; the separate approaches are supporting and are not affecting each other negatively. The heating demand in Kiruna is much higher than in Stuttgart and the additional heat gains due to adjustments of the building design are lower. Therefore, the achieved savings in the optimum case in Kiruna is $2.5 \%\left(66.70 \mathrm{kWh} / \mathrm{m}^{2} \mathrm{a}\right.$ heating demand and $0.97 \mathrm{kWh} / \mathrm{m}^{2}$ a for artificial lighting). The theoretical savings by assessing the separate approaches is the same $(2.5 \%)$. The optimum iterations in Palermo reduce the cooling demand by $21.5 \%$ to $30.58 \mathrm{kWh} / \mathrm{m}^{2}$ a while the theoretical savings by assessing the separate approaches is $26.6 \%$. In the Italian case there are some negative interactions between the best separate approaches when they are combined. A minor impact on the overall energy demand has the combination of daylighting control and controlled shading; if controlled shading is installed, daylighting control does not have a major impact on the energy demand. Furthermore, by orienting the building to the north, the cooling demand is already reduced, and additional measures have lower saving effects in absolute numbers than in a building oriented to the south (additional shading, natural ventilation).

\section{DISCUSSION AND CONCLUSION}

Passive approaches to minimize the energy demand of buildings (mainly heating and cooling, but also lighting) can have a large impact on the specific and overall energy demand and are therefore crucial for the realization of cost effective nearly zero-energy buildings. A major advantage of passive 


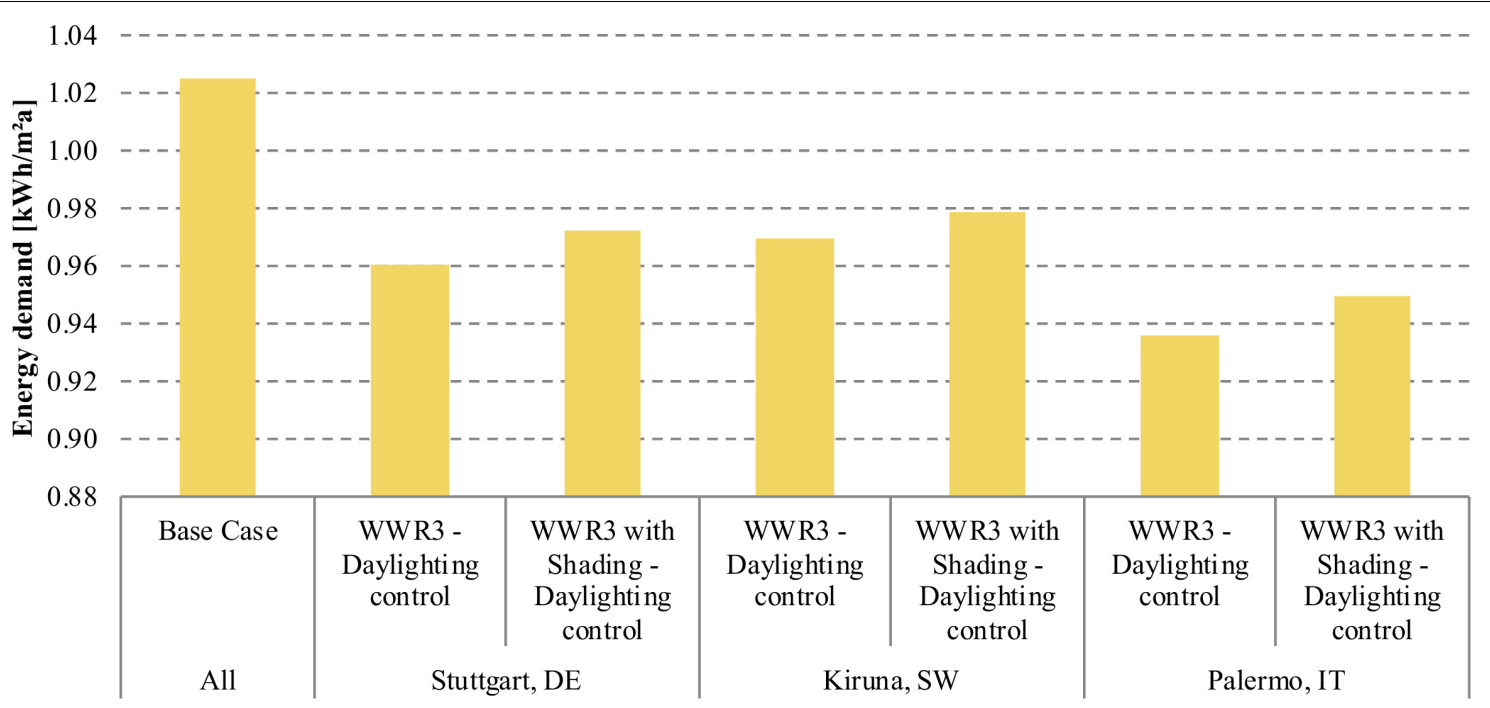

FIGURE 2 | Electricity demand for lighting due to the use of daylighting control and effect of additional fixed external shading in the three assessed climate regions.

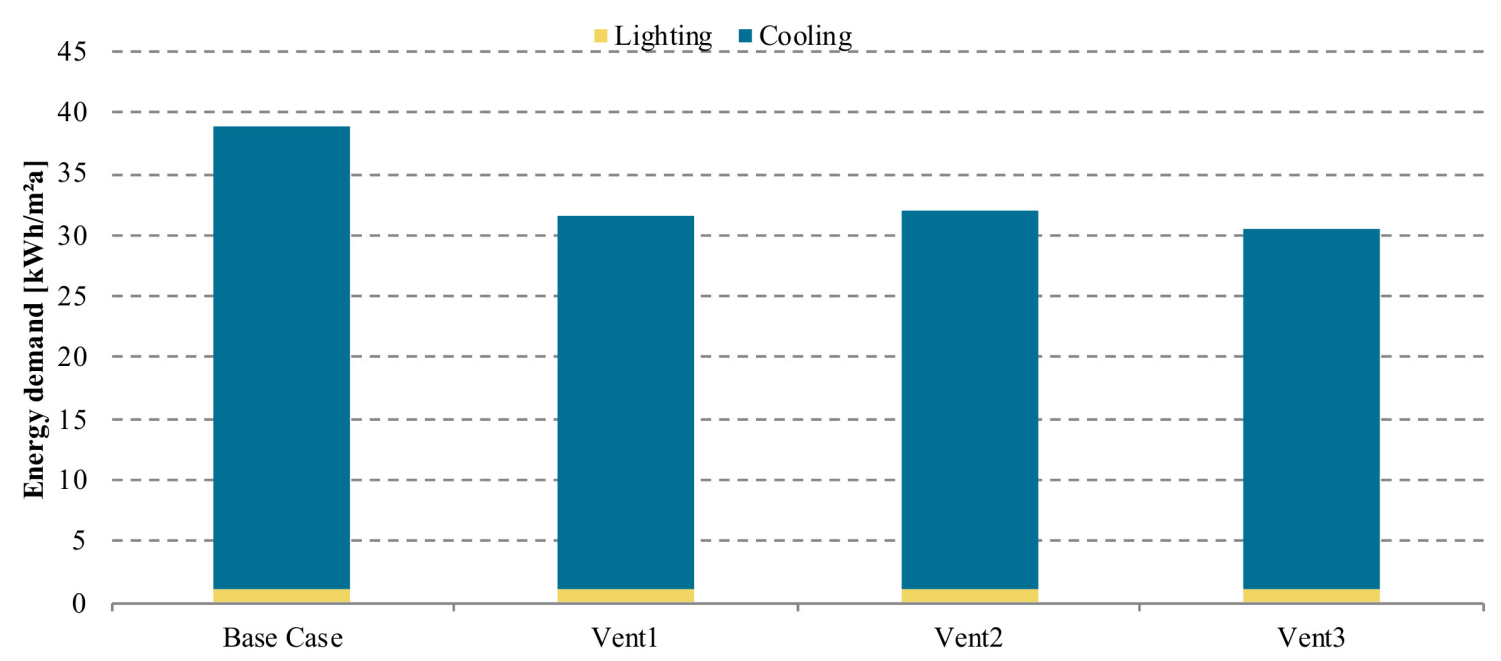

FIGURE 3 | Cooling and electricity for lighting demand due to the implementation of natural ventilation strategies in Italy.

(design) approaches is that many are associated with no or low additional costs and can therefore lower the life cycle costs of nZEBs. Which approaches are suitable for a building is highly depending on the climate conditions and the respective main energy demand (heating or cooling). Furthermore, the applicability and possibility to design and orient a building optimally with respect to local climate conditions might be limited by other site conditions (road orientation, neighboring buildings, requirements from municipalities etc.).

The optimum iterations for each assessed passive approach in the different climate regions are listed in "Optimum Combinations." While a south orientation together with comparably high window to wall ratio has a positive effect on the heating energy demand in moderate and cold climates, this combination would lead to strong increases in the cooling demand in southern climate regions, in which cooling is the dominating factor. In southern climates an orientation to the north together with a low window to wall ratio leads to best results.

Using daylighting control positively affects the electricity demand for lighting in all climate regions. Even though the relative savings are comparably high, the effect on the total energy demand is low as the lighting energy demand only plays a minor role in the assessed building. Therefore, the building design should be optimized regarding the heating or cooling energy demand rather than focusing on minimizing the electricity demand for lighting. If daylighting control is used in a building, additional fixed external shading can slightly increase the electricity demand for lighting in all locations. However, 


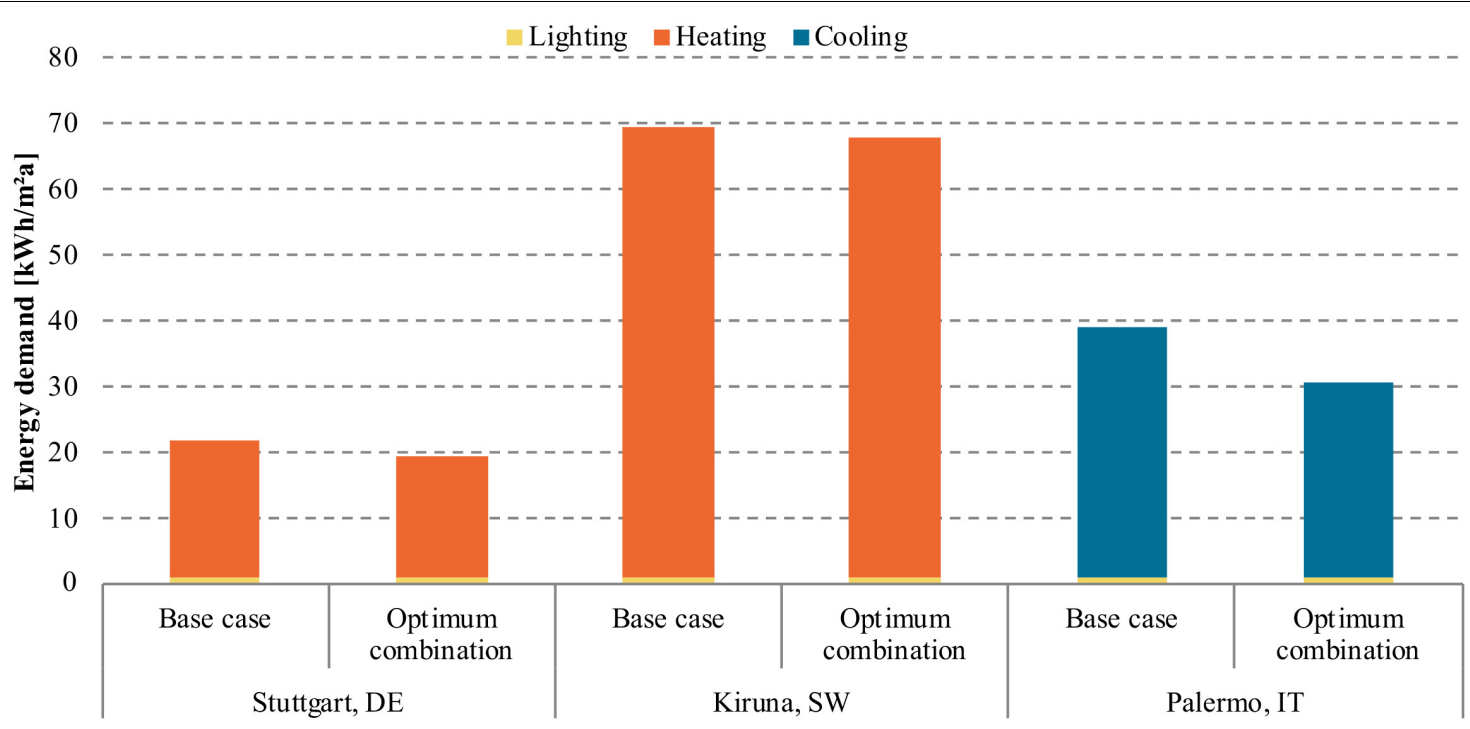

FIGURE 4 | Heating, cooling, and electricity for lighting demand for the combination of the best variations in comparison to the base case in the three assessed climate regions.

they do have positive effects on (i) comfort conditions with respect to glare and overheating and (ii) on the cooling demand if cooling systems are installed. Therefore, incorporating fixed external shading (e.g., overhangs) in the design of the building façade especially in southern climate regions positively influences the total energy demand and comfort.

When combining the best approaches in moderate and cold climate conditions, the overall savings slightly increase compared to the assessment of separate approaches. This indicates that the different approaches support each other in the goal of minimizing the overall energy demand. This is the case when focusing on heating and lighting energy demand. If cooling energy demand, which is currently not important in residential buildings in Stuttgart, is considered as well, the results change. An increased WWR is strongly increasing the cooling demand and this increase is higher than the savings in the heating demand. Therefore, if cooling becomes more important in residential buildings also in moderate climates, too large window areas should be avoided. The strong negative effect of large window areas on the cooling demand was already observed for the Italian case.

The assessed approaches are mainly focusing on the building design and envelope. However, there are several topics, which could further improve the performance of a building with respect to electricity demand for lighting, heating as well as cooling and should be assessed in the future. The differences in energy use between best approaches and worst approaches are small. Other issues like increasing the insulation thickness, install other window types, add movable shading and the installation of highly efficient building technologies (heat pumps etc.) can have much higher impacts. Essential is the efficient supply of the remaining energy making use of on-site renewable energy as much as possible. Possible technologies in this context are geothermal heat, reversible heat pumps, photovoltaic and solar thermal collectors. An optimization of these active technologies as well as other side conditions like e.g., the user behavior was assessed in another work package of the CRAVEzero project and are available in the respective deliverables (Venus et al., 2019; Weiß et al., 2019).

\section{DATA AVAILABILITY STATEMENT}

The raw data supporting the conclusions of this article will be made available by the authors, without undue reservation.

\section{AUTHOR CONTRIBUTIONS}

EE contributed the concept and design of the study, wrote the first draft of the manuscript, and involved in the revisions of the article. BK supervised the work of EE and provided guidance and revision. Both authors together conducted the simulation work and analysis of the results together. Both authors contributed to the article and approved the submitted version.

\section{FUNDING}

The work presented in this manuscript is developed in the frame of the EU funded project CRAVEzero - Cost Reduction and market Acceleration for Viable nearly zeroEnergy buildings which is co-funded by the Intelligent Energy Europe Programme within the Horizon 2020 Framework Programme of the European Union under Grant Agreement No. 741223. 


\section{ACKNOWLEDGMENTS}

The authors thank Mr. Giovanni Tumminia from the Italian National Research Council Institute for Advanced Energy Technologies "Nicola Giordano" and Mr. Mustafa

\section{REFERENCES}

Artmann, N., Manz, H., and Heiselberg, P. (2007). Climatic potential for passive cooling of buildings by night-time ventilation in Europe. Appl. Energy 84, 187-201. doi: 10.1016/j.apenergy.2006.05.004 doi: 10.1016/j.apenergy.2006. 05.004

Attia, S. (2018). Net Zero Energy Buildings (NZEB): Concepts, Frameworksand Roadmap for Project Analysis and Implementation. Oxford, CA: ButterworthHeinemann.

Birtles, A. B., Kolokotroni, M., and Perera, M. (1996). Night cooling and ventilation design for office-type buildings. Renew. Energy 8, 259-263. doi: 10.1016/09601481(96)88858-88856

Buildings Performance Institute Europe [BPIE] (2011). Principles for Nearly Zero Energy Buildings: Paving the Way for Effective Implementation of Policy Requirements. Brussels: BPIE.

Cabeza, L. F., and Chàfer, M. (2020). Technological options and strategies towards zero energy buildings contributing to climate change mitigation: a systematic review. Energy Build. 219:110009. doi: 10.1016/j.enbuild.2020. 110009

Engelmann, P., Kalz, D., and Salvalai, G. (2014). Cooling concepts for non-residential buildings: a comparison of cooling concepts in different climate zones. Energy Build. 82, 447-456. doi: 10.1016/j.enbuild.2014. 07.011

European Union (2010). Directive 2010/31/EU of the European Parliament and of the Council of 19 May 2010 on the Energy Performance of Buildings. Brussels: European Union.

Federal Ministry for Economic Affairs and Energy (2015). BMWi Broschüre Energieeffizienzstrategie Gebäude, Berlin, 92 pp. Available online at: https://www.bmwi.de/Redaktion/DE/Publikationen/Energie/ energieeffizienzstrategie-gebaeude.pdf?_blob=publicationFile\&v=15 (accessed March 29, 2018)

Ferrara, M., Monetti, V., and Fabrizio, E. (2018). Cost-optimal analysis for nearly zero energy buildings design and optimization: a critical review. Energies 11:1478. doi: 10.3390/en11061478

Gago, E. J., Muneer, T., Knez, M., and Köster, H. (2015). Natural light controls and guides in buildings. Energy saving for electrical lighting, reduction of cooling load. Renew. Sustain. Energy Rev. 41, 1-13. doi: 10.1016/j.rser.2014. 08.002

Kolokotroni, M., Perera, M. D. A. E. S., Azzi, D., and Virk, G. S. (2001) An investigation of passive ventilation cooling and control strategies for an educational building. Appl. Therm. Eng. 21, 183-199. doi: 10.1016/S13594311(00)00008-9

licht.de (2008). Licht.Wissen 01: Die Beleuchtung mit Künstlichem Licht, Frankfurt/Main. Available online at: https://www.licht.de/fileadmin/ Publikationen_Downloads/1603_lw01_Kuenstliches-Licht_web.pdf doi: 10.1016/s1359-4311(00)00008-9 (accessed April 10, 2019).

Salvalai, G., Pfafferott, J., and Sesana, M. M. (2013). Assessing energy and thermal comfort of different low-energy cooling concepts for non-residential buildings. Energy Conver. Manag. 76, 332-341. doi: 10.1016/j.enconman.2013. 07.064
Abunofal from Fraunhofer ISE, who supported with setting up the simulation model and therefore gave very valuable input. Furthermore, the authors thank Dr. Peter Engelmann and Sebastian Herkel for the ISE-internal review of the manuscript.

Schulze, T., and Eicker, U. (2013). Controlled natural ventilation for energy efficient buildings. Energy Build. 56, 221-232. doi: 10.1016/j.enbuild.2012. 07.044

The European Parliament and The Council of the European Union (2018). Directive (EU) 2018/844 of the European Parliament and of the Council of 30 May 2018 amending Directive 2010/31/EU on the Energy Performance of Buildings and Directive 2012/27/EU on Energy Efficiency. Brussels: The European Parliament.

Tzortzaki, A. (2017). Nearly Zero Energy Buildings: Comparison of the Targets Set by the European Countries and Analysis of Their Diffusion. Master thesis, University in Milan, Milan.

Venus, D., Weiß, T., Moser, C., Garzia, F., Pernetti, R., Torriglia, D., et al. (2019). Results of Optimised nZEB Parametric Models. AEE - Institute for Sustainable Technologies; Eurac Research Institute for Renewable Energy; $3 i$ Engineering, Gleisdorf, Bolzano, Alessandria, 143 pp. Available online at: www.cravezero.eu/wpcontent/uploads/2019/09/CRAVEzero_D62_Results_of_parametric \%20models.pdf (accessed September 17, 2019).

American Society of Heating, Refrigerating and Air-Conditioning Engineers, U.S. Department of Energy's, and National Renewable Energy Laboratory (2001). Weather Data by Region | EnergyPlus. Result of ASHRAE Research Project 1015. Available online at: https://energyplus.net/weather-region/europe_wmo_ region_6 (accessed May 11, 2020).

Weiß, T., Moser, C., Venus, D., Garzia, F., Pernetti, R., Köhler, G., et al. (2019). Parametric Models for Buildings and Building Clusters: Building Features and Boundaries. AEE - Institute for Sustainable Technologies; Eurac Research Institute for Renewable Energy; Köhler \& Meinzer GmbH \& Co KG Wohnungsunternehmen, Gleisdorf, Bolzano, Eggenstein-Leopoldshafen, 79 pp. Available online at: www.cravezero.eu/wpcontent/uploads/2019/03/CRAVEzero_D61_Parametric_models.pdf (accessed September 17, 2019).

Wietschel, M., Arens, M., Dötsch, C., Herkel, S., Krewitt, W., Markewitz, P. et al. (2010). Energietechnologien 2050 - Schwerpunkte für Forschung und Entwicklung: Technologienbericht, Stuttgart. Available online at: http://publica. fraunhofer.de/dokumente/N-118535.html (accessed April 10, 2019).

Zissis, G. (2019). "Energy consumption and environmental and economic impact of lighting: the current situation," in Handbook of Advanced Lighting Technology, eds R. Karlicek, C.-C. Sun, G. Zissis, and R. Ma (Cham: Springer), 1-13. doi: 10.1007/978-3-319-00295-8_40-1

Conflict of Interest: The authors declare that the research was conducted in the absence of any commercial or financial relationships that could be construed as a potential conflict of interest.

Copyright (c) 2020 Elnagar and Köhler. This is an open-access article distributed under the terms of the Creative Commons Attribution License (CC BY). The use, distribution or reproduction in other forums is permitted, provided the original author(s) and the copyright owner(s) are credited and that the original publication in this journal is cited, in accordance with accepted academic practice. No use, distribution or reproduction is permitted which does not comply with these terms. 